\title{
Political advertising revisited: digital campaigning and protecting democratic discourse
}

Michael Harker, Professor of Law, UEA Law School; m.harker@uea.ac.uk

Abstract

This article is concerned with the legal and regulatory control of electoral campaigning online, in particular 'microtargeting'. There has been a longstanding consensus in the UK on how to control political advertising, yet the shift of expenditure to the online environment, together with innovations in digital campaigning tools, are exposing tensions and gaps in the current regime. One central harm associated with microtargeting is its potential to undermine meaningful democratic deliberation. The article interrogates the issues through the lens of electoral law and regulation, and questions the extent to which a recalibration is necessary to deal with the challenges of digital campaigning.

Keywords: public law (SLS); political advertising; microtargeting; electoral law

Legislation: Article 10 ECHR; Political Parties, Elections and Referendums Act 2000;

Communications Act 2003

\section{INTRODUCTION}

Political advertising in the UK is undergoing radical change, challenging a longstanding regulatory framework. Restrictions on political advertising have a long provenance, dating back to the nineteenth century, but in more recent times emphasis has shifted to the control of mass 
media campaigning tools. In terms of the normative basis of regulation, the system seeks, on the one hand, to protect freedom of expression, while on the other, it ensures the democratic system is not distorted by powerful interest groups. The ban on political advertising on broadcast media was for many years core to the regulatory framework, as a means of ensuring that there was no electoral 'arms race' in advertising expenditure. ${ }^{1}$ Restrictions on party spending has been another flank of regulation; the growth of national media campaigns tended to eschew strict limits on constituency-level campaign expenditure. This was remedied by the introduction of legislation in 2000 imposing national campaign spending caps supervised and enforced by a new regulator, the Electoral Commission (ELC).

While for a period relatively stable, in recent years it has been suggested electoral law is in need of substantial reform to deal principally with the shift to digital advertising, particularly the use of data to target individual voters with tailored political messages (so-called 'microtargeting'). ${ }^{2}$ The case for reform is gaining traction, with the ELC publishing a raft of proposals, albeit modest in nature. ${ }^{3}$ The controversies surrounding microtargeting are part of the broader debate on online disinformation (aka 'fake news'), and it is often analysed in that context. In that regard, there have been a plethora of other reports and investigations which have touched on the issue of microtargeting, notably the House of Commons Digital, Culture Media and Sport

\footnotetext{
${ }^{1}$ Fifth Report of the Committee on Standards in Public Life The Funding of Political Parties in the United Kingdom Cm 4057-I, October 1998 (hereafter the 'Neill Committee') para 13.11.

${ }^{2}$ Council of Europe Study on the use of internet in electoral campaigns, Council of Europe study (DGI(2017) April 2018) p 23 (hereafter 'CoE report').

${ }^{3}$ Electoral Commission Digital campaigning: Increasing transparency for voters (June 2018).
} 
Committee's (DCMSC) inquiry ${ }^{4}$ and the EU Commission's initiatives, ${ }^{5}$ including the adoption of a code of practice. ${ }^{6}$

Microtargeting also raises serious issues concerning individuals' privacy and data protection rights. ${ }^{7}$ Even the most casual observer cannot have escaped the press coverage, parliamentary scrutiny and regulatory action taken with respect to the alleged misuse of data in recent elections and referendums. ${ }^{8}$ While of the upmost importance, for the purposes of this article, the question of the legality of the procuring and use of personal data will not be discussed directly. ${ }^{9}$

${ }^{4}$ House of Commons Digital, Culture, Media and Sport Committee Disinformation and 'fake news': Interim Report, Fifth Report of Session 2017-19, HC 363, 29 July 2018 (hereafter 'DCMSC interim report'); House of Commons Digital, Culture, Media and Sport Committee Disinformation and 'fake news': Final Report, Eighth Report of Session 2017-19, HC 1791, 14 February 2019 (hereafter 'DCMSC final report'); ${ }^{5}$ Commission Communication Tackling Online Disinformation: A European Approach, COM(2018)236 final) pp 7-8; EU Commission Action Plan against Disinformation (JOIN(2018) 36 final); European Commission A multi-dimensional approach to disinformation: Report of the independent High Level Expert Group on Fake News and Online Disinformation (March 2018) pp 12, 22.

${ }^{6}$ EU Commission, EU Code of Practice on Disinformation (26 September 2018) (hereafter 'EU CoP') available at: https://ec.europa.eu/digital-single-market/en/news/code-practice-disinformation ${ }^{7}$ For a discussion see: Information Commissioner's Office Democracy disrupted? Personal information and political influence (11 July 2018); European Data Protection Supervisor Opinion on online manipulation and personal data (Opinion 3/2018) (hereafter 'EDPS report').

${ }^{8}$ For an overview see Emily Haves Personal Data, Social Media and Election Campaigns (Lords Library notes LLN-2018-0061, 13 June 2018).

${ }^{9}$ The Information Commissioner's Office (ICO) is currently investigating several organisations concerning the use of data analytics for political purposes and potential breaches of data protection law, including 
Rather, the central focus of this article is on whether such techniques have the potential to distort the public discourse and subvert the democratic process, and if so, how should the law respond. The analysis here is on the regulation of political parties and campaign groups who seek to influence electoral outcomes directly, rather than broader forms of political expression online. Such a distortion may result from the unmediated nature of the messages. First, targeted advertisements can escape the attention of the media and the public such that political campaigns may make contradictory claims to different segments of the electorate. Second, messages may be designed to play to some voters' prejudices and biases without any exposure to countervailing viewpoints. This may lead to a greater polarisation and fragmentation of society, and ultimately undermine the ability of voters to engage in meaningful democratic deliberation. ${ }^{10}$ The evidence which exists is considered in more detail in the next section. One of the key questions is whether intervention can be justified on the basis of risk rather than proof of actual harm. A further problem relates to the need to avoid regulation which limits political discourse online. There are also inherent dangers in seeking to restrict or control the content of political speech. ${ }^{11}$ Measures which seek to maximise transparency for voters, while exposing political messages to public

alleged criminal offences. In this connection, Facebook has been fined $£ 500,000$ (the maximum civil penalty) for breaches of Data Protection Act 1998. For further information see: https://ico.org.uk/aboutthe-ico/news-and-events/news-and-blogs/2018/10/facebook-issued-with-maximum-500-000-fine/ ${ }^{10}$ For a discussion see J Habermas 'Political Communication in Media Society: Does Democracy Still Enjoy an Epistemic Dimension? The Impact of Normative Theory on Empirical Research' (2006) 16 Communication Theory 411.

11 Of course, this may be necessary in certain circumstances (eg, hate speech). 
scrutiny, should always be preferred over more restrictive controls. The policy dilemma arises when such measures prove to be ineffective.

In terms of the dimensions of the problem and possible solutions, there a number of options. First, there are measures to increase the transparency of digital messages enabling voters to judge the credibility of targeted messages on the basis of their provenance and whether they have been paid for. The use of online repositories may also lead to greater scrutiny of the messages targeted. Second, reforms could be made to the reporting requirements political campaigners are required to follow, and tighter restrictions on advertising from outside the UK. There remains a third approach, which is to place substantive restrictions on online advertising. In designing any interventions, great care would be needed to minimise any limits on political expression. The case for substantive restrictions should not be ruled out, however, especially if other less interventionist measures prove to be unworkable or are subverted. The problems also raise classic concerns of regulatory theory, in particular: regulatory fragmentation, since responsibility for regulation is likely to be dispersed across different actors (government, agencies, and crucially the industry); ${ }^{12}$ information asymmetries, given the techniques used are characterised

\footnotetext{
12 J Black 'Enrolling Actors in Regulatory Systems: Examples from UK Financial Services Regulation' [2003] PL 63. For a detailed explanation of the digital advertising industry see: S Adshead, G Forsyth, S Wood, L Wilkinson Online advertising in the UK (Plum/DCMS, January 2019) available at: https://assets.publishing.service.gov.uk/government/uploads/system/uploads/attachment data/file/77799 6/Plum DCMS Online Advertising in the UK.pdf
} 
by high levels of innovation; and the costs of regulatory failure, which are particularly high here given the potential harm to the democratic process.

\section{A PRIMER ON MICROTARGETING}

This section explains the 'mechanics' of microtargeting, identifies the key actors, how it is used, and its possible effects, both negative and positive. ${ }^{13}$ As a cautionary note, the negative effects of microtargeting should neither be assumed nor exaggerated. The literature overall tends to frame new innovations in political campaigning in pessimistic terms. The intention here is to expose the risks to enable a discussion of if and how to design appropriate legal responses.

Targeting of voters is by no means a new phenomenon. Political parties have for many years collected data on voters, dividing them into segments based on their characteristics (in particular, geographic, demographic and previous voting behaviour), with a view to designing specific political content for each segment. ${ }^{14}$ The difference with microtargeting is the potential: to bring

\footnotetext{
${ }^{13}$ In line with the scope of this article, the obvious threats to privacy and data protection rights are not discussed here.

${ }^{14}$ International Institute for Democracy and Electoral Assistance Digital Microtargeting: Political Party Innovation Primer (Stockholm: IDEA, 2018) p 10 (hereafter IDEA). On the changing models of campaigning, from mass-centred to individual-centred campaigns, see S Kruschinski and A Haller 'Restrictions on data-driven political micro-targeting in Germany' (2017) 6(4) Internet Policy Review available at https://policyreview.info/articles/analysis/restrictions-data-driven-political-micro-targetinggermany
} 
together data from various sources (or 'datapoints'), to draw inferences about political beliefs and biases from seemingly unrelated data (such as internet browsing and purchases), to target messages to voters at a high level of granularity, to test the efficacy of campaign messages in real time, and to differentiate messages to particular voters. We also know, as elections become 'datafied', political campaigners are increasingly reliant on digital intermediaries, whose influence over the democratic process may be problematic. ${ }^{15}$

(a) The key techniques of microtargeting

What follows is a brief sketch of the key methods of microtargeting, the different types of intermediaries involved, and their respective roles. ${ }^{16}$

\section{(i) DATA COLLECTION AND AGGREGATION}

Political parties have traditionally maintained information on individual voters, gathering information from public sources (principally the electoral register), together with their own canvassing data. Other data is gathered from various other commercial sources, including on: geographic location, basic demographic data (age, gender, income, education etc); search and online activity (which can be used to identify a voter's specific political interests or leanings, or

15 J Bartlett, J Smith and R Acton The future of political campaigning (DEMOS, July 2018) p 26.

${ }^{16}$ For an overview see: IDEA, above n 14, pp 10-16; D Tambini 'Social Media Power and Election Legitimacy' in M Moore and D Damian Tambini (eds) Digital Dominance: The Power of Google, Amazon, Facebook, and Apple (Oxford: OUP, 2018) pp 274-278; EDPS report, above n 7, pp 7-9. 
seemingly less relevant information, such as online purchasing behaviour). ${ }^{17}$ As has been the case for a number of years, growing out of commercial online advertising, there are a number of 'data brokers' supplying data for political advertising. ${ }^{18}$ The platforms themselves also collect and aggregate data on their users, facilitating targeting. Data exchanges, which provide for the automated buying and placing of digital advertisements through real-time 'auctions' (so-called 'programmatic advertising'), also exploit large amounts of data held on individuals. ${ }^{19}$

\section{(ii) VOTER SEGMENTATION AND PROFILING}

Voter segmentation means 'dividing the electorate into smaller blocks, and using different campaign methods for each segment' ${ }^{20}$ While not a new practice, it is becoming increasingly efficient due, first, to the high level of granularity of the data which is now collected and, second, the sophisticated methods of profiling which can be employed.

There are two principal means of profiling. Personal data can be used to predict political views and party allegiances, the probability of voting, and which issues are likely to have particular resonance with individuals ('predictive' profiling). More controversially, what is referred to as

\footnotetext{
17 For a detailed account of the online advertising industry, see Adhead et al., above n 12.

18 See ICO, above n 9, p 58.

${ }^{19}$ Bartlett et al., above n 15, p 7; J Chester and KC Montgomery 'The role of digital marketing in political campaigns' (2017) 6(4) Internet Policy Review available at https://policyreview.info/articles/analysis/roledigital-marketing-political-campaigns

20 IDEA, above n 14, p 12.
} 
'psychographic' profiling is increasingly employed, a technique whereby data analytics firms profile voters according to personality traits. ${ }^{21}$ In terms of data collection, one method is to incentivise people to undertake personality tests, and then cross-reference results with other online or personal data. ${ }^{22}$ Psychographic data can also be inferred from online behaviour more generally. Although the veracity and effectiveness of such techniques is currently a matter of debate,${ }^{23}$ its use in political campaigning is well documented, especially its potential to achieve greater precision of salient and persuasive messages. ${ }^{24}$

While many of the techniques involved in microtargeting are controversial, 'lookalike modelling' has attracted particular opprobrium. This technique enables campaigners to reach new audiences on platforms (referred to as 'peer groups' or 'persuadables') due to their sharing similar characteristics or profiles to existing audiences ('cloning'); ${ }^{25}$ Facebook offers a 'lookalike' service which has been used by political campaigns. ${ }^{26}$

(iii) CREATING AND TESTING PERSONALISED MESSAGES

${ }^{21}$ EDPS report, above $\mathrm{n} 7, \mathrm{p} 8$

22 Bartlett et al., above n 15, p 21.

${ }^{23}$ EDPS report, above n 7, p 9.

${ }^{24}$ Bartlett et al., above n 15, pp 1-22, 31 (and the references cited therein).

${ }^{25}$ Chester and Montgomery, above n 19.

${ }^{26}$ Bartlett et al., above n 15, p 28; EDPS report, above n 7, p 8. 
As was noted above, a key advantage of microtargeting is the increased precision and efficiency of targeting. One of the reasons for this is the testing of messages on an iterative basis through the use of algorithms (so-called 'A/B testing'). While campaign messages have long been subject to testing to maximise their resonance with voters (especially through focus groups), the use of social media and commercial advertising methodologies has resulted in a 'step change in pace and scale'. ${ }^{27}$ One of the disturbing effects of such technology is said to be the dislocation of the politicians from any effective engagement with, or understanding of, the electorate. ${ }^{28}$

(b) The potential benefits and harms of microtargeting ${ }^{29}$

Microtargeting may lead to a levelling of the political playing field and a greater diversity of viewpoints. Political parties benefit from more precise targeting, reducing costs and possibly lowering barriers for smaller parties to reach the electorate. ${ }^{30}$ With a shift away from mass

\footnotetext{
${ }^{27}$ Bartlett et al., ibid, p 33.
}

28 WA Gorton 'Manipulating Citizens: How Political Campaigns' Use of Behavioral Social Science Harms Democracy' (2016) 38(1) New Political Science 61, 70.

${ }^{29}$ For a discussion see: FJ Zuiderveen Borgesius, J Möller, S Kruikemeier, RÓ Fathaigh, K Irion, T Dobber, B Bodó and C de Vreese 'Online Political Microtargeting: Promises and Threats for Democracy' (2018) 14 Utrecht Law Review 82, 84-89; B Bodó, N Helberger and CH de Vreese 'Political microtargeting: a Manchurian candidate or just a dark horse?' (2017) 6(4) Internet Policy Review available at https://policyreview.info/articles/analysis/political-micro-targeting-manchurian-candidate-or-just-darkhorse.

${ }^{30}$ Cf. N Anstead ‘Data-Driven Campaigning in the 2015 United Kingdom General Election' (2017) 22(3) The International Journal of Press Politics 294, 308. 
media, political campaigns may also become more diverse, as parties seek to engage voters on issues which previously had been regarded as of marginal relevance. Indeed, one of the lauded benefits of social media platforms (SMPs) is their facilitating the greater participation of individuals in political campaigns, and a wider prevalence of 'satellite campaigns' advocating particular electoral outcomes while being outside the control of the political parties themselves. ${ }^{31}$ Voters in turn may become more engaged and likely to vote as campaign messages are tailored more effectively to their interests and concerns. Taken together, such effects may lead to greater electoral participation.

According to Gorton, given the ability of microtargeting to alter voter behaviour, citizens become "potential objects of control rather than autonomous political actors'. ${ }^{32}$ Even if this is true, of more concern is the effect this could have on public discourse; the ability to segment voters and target individualised messages may lead to a fragmentation of political debate, and a polarisation of the electorate..$^{33}$

For a number of years now, partly because of their commercial models, concern has been expressed that the use of online intermediaries can lead to the related phenomena of 'filter

\footnotetext{
${ }^{31}$ For a discussion see K Dommett and L Temple 'Digital Campaigning: The Rise of Facebook and Satellite Campaigns' (2018) 71 Parliamentary Affairs 189.

32 Gorton, above n 28, p 63.

${ }^{33}$ D Kreiss 'Yes We Can (Profile You): A Brief Primer on Campaigns and Political Data' (2012) 64 Stan L Rev Online 70, 74; Gorton, above n28, p 63; Zuiderveen Borgesius et al., above n 29, p 87; CoE report, above $\mathrm{n} 2, \mathrm{p} 18$.
} 
bubbles' and 'echo chambers'. ${ }^{34}$ It is true to say that the evidence is ambiguous. ${ }^{35}$ Some have found some modest effects, ${ }^{36}$ while others have found vulnerable users may be particularly susceptible. ${ }^{37}$ In any event, filter bubbles are materially different from political microtargeting. The former is a product of the platforms' algorithms, optimising the salience of messages in order to maximise commercial gains from advertising. The latter is concerned explicitly with selecting the relevant audience, according to their political opinions, and tailoring campaign messages in order to influence their voting intentions.

Traditionally, the electorate have tended to gather information via the mass media, whereas microtargeting offers the ability to tailor (unmediated) messages to voters according to their pre-

${ }^{34}$ C Sunstein Republic.Com 2.0 (New York: Princeton UP, 2009); For a literature review see FJ Zuiderveen Borgesius, D Trilling, J Moeller, B Bodó, CH de Vreese, and N Helberger 'Should We Worry About Filter Bubbles?' (2016) 5(1) Internet Policy Review available at https://policyreview.info/ ${ }^{35}$ For a review of the evidence see: D Spohr 'Fake news and ideological polarization: Filter bubbles and selective exposure on social media' (2017) 34(3) Business Information Review 150. Some question whether there is robust empirical evidence that filter bubbles can shape voter preferences: Zuiderveen Borgesius et al., n 29 above; E Dubois and G Blank 'The echo chamber is overstated: the moderating effect of political interest and diverse media' (2018) 21(5) Information, Communication \& Society 729. ${ }^{36}$ S Flaxman, S Goel and JM Rao 'Filter Bubbles, Echo Chambers, and Online News Consumption' (2016) 80(1) Public Opinion Quarterly 298; R Fletcher and RK Nielsen 'Are people incidentally exposed to news on social media? A comparative analysis' (2018) 20(7) New Media \& Society 2450; M Gentzkow and JM Shapiro 'Ideological Segregation Online and Offline' (2011) 126(4) The Quarterly Journal of Economics 1799.

${ }^{37}$ WH Dutton and L Fernandez 'How Susceptible Are Internet Users? (2019) 46(4) Intermedia 36. 
existing political preferences and biases. ${ }^{38}$ This has the potential to fragment the public sphere by reducing the opportunities for voters to engage in a shared public discourse. ${ }^{39}$ Instead of promoting a common conversation, campaigns tend to focus on 'wedge issues' - the promotion of emotive and superficial matters - which may distort public debate and lead to greater insularity. ${ }^{40}$

Furthermore, as targeting becomes more efficient, there is an increased tendency to focus on those voters who are most useful to the campaign, excluding others. For this reason, microtargeting is particularly effective in first-past-the-post electoral systems where resources tend to be focused on key marginal seats. ${ }^{41}$ 'Political redlining' is a technique employed by campaigns where they concentrate on 'swing' voters in target constituencies, ignoring others who are likely to support opposing parties, or are least likely to vote. ${ }^{42}$ The danger is this exacerbates pre-existing political inequalities by ignoring voters who are least likely to be

38 Gorton, above n 28, p 71 .

39 IS Rubinstein 'Voter Privacy in the Age of Big Data' (2014) 5 Wis L Rev 861, 910; Anstead, above n 30, pp 308-309.

40 Rubinstein, ibid, p 909; CoE report, above n 2, p 18.

${ }^{41}$ However, there is evidence that microtargeting it has been used successfully in countries which have proportional representation electoral systems, see: Kruschinski and Haller, above n 14; M Magin, N Podschuweit, J Haßler and U Russmann 'Campaigning in the fourth age of political communication' (2017) 20(11) Information, Communication \& Society 1698.

42 The term was coined by P Howard New Media Campaigns and the Managed Citizen (Cambridge: CUP, 2006). 
engaged. ${ }^{43}$ Microtargeting may also lead to the suppression of voter turnout for opposing campaigns; ${ }^{44}$ a practice referred to as 'digital gerrymandering'. ${ }^{45}$ While negative campaigning is not new, the increased efficiency of microtargeting increases the adverse consequences in terms of voter disengagement.

Another issue relates to the power of the intermediaries. In recent years, as politicians have realised the advantages of digital marketing, there has been a significant growth in big data experts and consultancies upon whom parties are reliant. Platforms themselves have developed services which are closely integrated with political parties' campaign teams, ${ }^{46}$ controlling access to the electorate with which political parties wish to communicate, their data, and targeting campaign tools. ${ }^{47}$ Facebook, in particular, appears to be emerging as a 'one-stop-shop' for services related to microtargeting. ${ }^{48}$ There are a number of possible dangers as intermediaries

\footnotetext{
${ }^{43}$ There is also some evidence that since it is rational to focus on those more likely to vote (especially older voters), it may have the consequence of leading to great voter disengagement in the longer-term ( $\mathrm{K}$ Endres and KJ Kelly 'Does microtargeting matter? Campaign contact strategies and young voters' (2018) 28(1) Journal of Elections, Public Opinion and Parties 1).

${ }^{44}$ Rubinstein, above n 39, pp 908-909.

${ }^{45}$ EDPS report, above $\mathrm{n} 7, \mathrm{p} 13$.

${ }^{46}$ For a discussion of the US see: D Kreiss and SC McGregor 'Technology Firms Shape Political Communication: The Work of Microsoft, Facebook, Twitter, and Google With Campaigns During the 2016 US Presidential Cycle' (2017) Political Communication 1; DW Nickerson and T Rogers 'Political Campaigns and Big Data' (2014) 28(2) Journal of Economic Perspectives 51.

${ }^{47}$ CoE report, above n 2, p 18.

${ }^{48}$ Tambini, above n 16, p 281.
} 
assume an increasingly powerful role as 'gatekeepers' over parties' abilities to communicate with voters. In contrast to (some of) the traditional media, there is little incentive on intermediaries to maintain a healthy public debate or a level playing field for political parties; 'political audiences are ultimately sold to the highest bidder' ${ }^{49}$ Another area for caution is the ability an intermediary has to refuse to deal with political parties whose viewpoints run counter to its own ideological standpoint. ${ }^{50}$ One related area of disquiet is 'political capture'. As politicians decide upon the regulatory environment in which intermediaries operate, the latter's increasing potential to shape electoral outcomes, in a setting which lacks transparency and public scrutiny, may result in the emergence of more favourable rules across all the spheres of their commercial activity, not simply those relating to political advertising. ${ }^{51}$ Conversely, a party which advocates greater regulation that is likely to damage the commercial interests of intermediaries may be discriminated against. ${ }^{52}$

Of all the possible risks from microtargeting, the most serious is the distortion of the democratic process by undermining public discourse. It may do this in two key ways. First, the collection and use of data may have a 'chilling effect' on voters' behaviour online, deterring them from expressing their opinions freely. ${ }^{53}$ Second, microtargeting may bypass the traditional media,

49 Bobo et al., above n 29; Kreiss and McGregor, above n 46, p 4.

50 Zuiderveen Borgesius et al., above n 29, p 89. There is anecdotal evidence from a former Facebook employee claiming to have been involved in suppressing conservative issues from trending on the platform in the US (CoE report, above n 2, p 18).

${ }^{51}$ Kreiss and McGregor, above n 46, pp 4-5.

52 Tambini, above n 16, p 282.

${ }^{53}$ EDPS report, above n 7, p 9; Kreiss, above n 33, p 71; Rubinstein, above n 39, pp 905-907. 
with political messages reaching voters without being mediated in any meaningful way; ${ }^{54}$ whereas previously a campaign may be deterred from propagating false or misleading information due to the potential adverse reputational effects; as messages become more targeted and differentiated, misleading information is less likely to be exposed. As Gorton cautions 'microtargeting produces messages that can more easily fly under the radar of the press and the broader public, markedly increasing their power to mislead and misinform viewers with impunity'. 55

The lack of transparency relating to the origin of an advertisement is likely to compound this problem. A 'dark ad' is a paid-for political message where only the publisher of the advertisement and the individual(s) targeted can see the message (unless she chooses to share the message with others), thus making it difficult to hold campaigners to account for any false or misleading information, and facilitating contradictory messages or policy claims. The term is also used to describe the situation where the target audience are unable to determine the provenance of the message and whether or not is it paid for. Conversely, technologies such as 'bots' can be used to artificially increase the apparent popularity of SMP accounts from which messages are sent, and fake accounts and paid trolls may also be used to deceive voters about the true level of a campaign's support (so-called 'astroturfing' ${ }^{56}$ ).

\footnotetext{
${ }^{54}$ CoE report, above $\mathrm{n} 2, \mathrm{p} 19$

55 Gorton, above n28, p 72.

${ }^{56}$ ELC, above n 3, para 24.
} 


\section{THE CURRENT LEGAL REGIME FOR THE REGULATION OF POLITICAL} ADVERTISING

This section gives a brief overview of the current rules which seek to control political advertising. First, there are controls on campaign expenditure which limit advertising spending by political parties and others. Second, the UK has maintained a longstanding prohibition of political advertising on television and radio. Third, the 'imprint' requirement, which currently applies only to printed materials, aims to increase the transparency of political advertising.

(a) Campaign expenditure rules ${ }^{57}$

Electoral law sets limits on the amount of money campaigners can spend on campaigns. There are two key pieces of legislation. Individual candidates' expenditure is governed by the Representation of the People Act 1983 (RPA). The spending limits at constituency level are relatively low. ${ }^{58}$ For this reason, parties would normally prefer to report advertising spending under the more generous national spending limits, even where a limited number of marginal seats are targeted.

National campaign expenditure, the focus here, is governed by the Political Parties, Elections and Referendums Act 2000 (PPERA), which also set up the ELC. Before PPERA there were no

\footnotetext{
57 The following is limited to elections to the UK Parliament and national referendums.

${ }^{58}$ For the 2017 general election this was set at $£ 8,700$ plus 6-9 pence per registered parliamentary elector.
} 
restrictions on national spending. The ELC has civil sanctions for unlawful behaviour, including fines (up to a maximum of $£ 20,000$ ). However, criminal offences can only be pursued by the police. ${ }^{59}$ The ELC's principal role is to enforce the reporting requirements for campaigners and ensure spending limits are not exceeded. Spending limits apply to expenditure during the 'regulated period' preceding the vote (eg, 12 months for the UK parliamentary elections, four months in respect of the 2016 EU referendum). The spending limit for a party contesting all UK parliamentary seats would be $£ 19.5$ million. ${ }^{60}$

In terms of national spending for the 2017 general election, of a total expenditure by registered parties of $£ 39,147,932$, around a quarter $(£ 10,052,016)$ was directly attributable to 'advertising', ${ }^{61}$ though this may be an understatement as advertising expenditure (including digital campaign spending) may fall within other reportable categories. ${ }^{62}$

\footnotetext{
59 The powers of the Electoral Commission were augmented by Political Parties and Election Act 2009.

60 ie, $£ 30,000$ for each seat (PPERA, Schedule 9).

61 This data was extracted from the ELC's online database of political spending: http://search.electoralcommission.org.uk/Search/Spending?currentPage=1\&rows=20\&sort=TotalExpendit ure\&order=desc\&tab=1\&et=pp\&includeOutsideSection75=true\&evt=ukparliament\&ev=3568\&optCols=Exp enseCategoryName\&optCols=AmountInEngland\&optCols=AmountInScotland\&optCols=AmountInWales\& optCols=AmountInNorthernIreland\&optCols=DatePaid

62 Particularly, 'Market research/canvassing' $(£ 7,364,272)$ and 'Unsolicited material to electors' $(£ 13,402,325)$.
} 
Third party spending is also regulated by PPERA. ${ }^{63}$ Where a non-party campaigner spends over a prescribed limit within the 'regulated period' (£20,000 in England), with the purpose of promoting particular candidates and/or policies aimed at influencing the outcome of an election, they must register with the ELC and comply with its reporting requirements on spending. ${ }^{64}$ Nonparty campaigners are only entitled to register if they are based in the UK; those not entitled to register must not spend above the prescribed spending limits.

Referendum spending under the EU referendum was also governed under PPERA. ${ }^{65}$ Here the ELC designated two lead campaign groups which were each subject to a spending limit of $£ 7$ million. Other registered campaigners (those spending over $£ 10,000$ ) were permitted to spend up to $£ 700,000$. Political parties were also entitled to register with the ELC provided they specified the outcome they were campaigning for; spending limits were based on the proportion of the vote in the preceding general election. ${ }^{66}$

In addition to spending, PPERA also put in place restrictions on donations and loans to political organisations (in both elections and referendums), which generally must originate with a person or organisation from the UK (where the amount exceeds £500). The ELC referred two

63 Significant changes were made under the Transparency of Lobbying, Non-Party Campaigning and Trade Union Administration Act 2014.

64 The limits for Scotland, Wales and Northern Ireland are $£ 10,000$.

${ }^{65}$ Specific rules were implemented under the European Union Referendum Act 2015.

${ }^{66} \mathrm{eg}$, the Labour Party had a spending limit of $£ 5.5 \mathrm{~m}$ (based on $29 \%$ of the vote in the 2015 general election). The Conservative Party did not register a preferred outcome so was not entitled to spend on the campaign. 
individuals to the National Crime Agency concerning alleged offences relating to illegal sources of funding and loans in the EU referendum. ${ }^{67}$

In terms of spending on digital advertising, the ELC noted social media had been used extensively in the EU referendum campaign, following the trend in the 2015 general election. ${ }^{68}$ Digital advertising spend (as a share of total advertising spend) has increased rapidly over the last decade: from 0.3 per cent in 2011 , to at least 42.8 per cent in $2017 .{ }^{69}$

(b) The prohibition on broadcast political advertising

The regulation of political advertising in the UK is the subject of a strict dichotomy; a complete ban with respect to broadcasting, and little or no regulation of everything else.

The statutory prohibition (now contained in the Communications Act 2003) (0) $^{70}$ as been in place since 1954 (the beginning of commercial television). It applies not only to organisations which

${ }^{67}$ ELC Report on investigation into payments made to Better for the Country and Leave.EU (1 November 2018).

${ }^{68}$ ELC Report on the regulation of campaigners at the referendum on the UK's membership of the European Union held on 23 June 2016 (March 2017) p 41. For further evidence of a substantial shift away from spending on traditional advertising to social media (in particular, Facebook), see: Tambini, above n 16, p 278 (on the EU referendum), and Anstead, above n 30 (on the 2015 general election). ${ }^{69}$ ELC, above n 3, p 4, chart 1 . This is likely to be under-reported as it refers only to direct expenditure on digital platforms.

70 Communications Act 2003, ss 319(2)(g) and 321(2). 
have political objectives, but all advertisements which have a 'political end', which has a very broad definition including influencing public opinion on a matter 'public controversy'. ${ }^{71}$

Broadcasters are, however, required to offer some campaigners free party political broadcasts. ${ }^{72}$ The UK's prohibition has been challenged, most notably in Animal Defenders International (ADI) $v U K$ (the 'ADI case'), ${ }^{73}$ where the Grand Chamber of the European Court of Human Rights ('the Court') upheld the ban (by a majority of nine to eight). ${ }^{74}$ This case is particularly pertinent for the future regulation of digital political advertising as the Court held a general prohibition may be permissible where less restrictive means of controlling advertising could lead to uncertainty or abuse. ${ }^{75}$ This point is elaborated upon below.

71 Communications Act 2003, s 321(3)(f).

72 Communications Act 2003, s 333. The right to a party political broadcast extends only to parties registered with the ELC, and referendum broadcasts are only made available to the designated lead campaigners (PPERA, ss 37 and 127, respectively).

73 (2013) 57 EHRR 21.

${ }^{74}$ For a discussion see T Lewis 'Animal Defenders International v United Kingdom: sensible dialogue or a bad case of Strasbourg jitters?' (2014) 77(3) MLR 460; J Rowbottom 'Animal Defenders International: speech, spending, and a change of direction in Strasbourg' (2013) 5(1) JML 1. The ban was challenged before the House of Lords ( $R$ (on the application of Animal Defenders International) $v$ Secretary of State for Culture, Media and Sport [2008] UKHL 15; [2008] 1 AC 1312) (for a discussion see T Lewis and P Cumper 'Balancing freedom of political expression against equality of political opportunity' [2009] PL 89). 75 There were several cases decided before $A D /$ which appeared to suggest a general prohibition could not be justified (especially, VgT Verien gegen Tierfabriken v Switzerland (2002) 34 EHRR 4 and TV Vest As \& Rogaland Pensjonistparti v Norway (2008) 48 EHRR 1206). The former case caused particular problems for the Government during the passage of the Communications Bill (Lewis, ibid, p 464). 
(c) The current 'imprint' requirement

At present, there is a requirement for an 'imprint' to appear on all printed election materials, ranging from unsolicited mail to newspaper advertisements. ${ }^{76}$ The imprint requirement serves two key purposes. First and foremost, it enables voters to judge the provenance and credibility of campaign materials. Second, it assists the ELC in monitoring and enforcing electoral spending rules.

'Election material' has a very broad meaning, defined as 'material which can reasonably be regarded as intended to promote or procure electoral success' of particular political parties or their candidates. ${ }^{77}$ It may include the advocacy of particular policies without mention of a particular candidate/party, ${ }^{78}$ or material 'prejudicing the electoral prospects at the election of other parties or candidates'. ${ }^{79}$ The 'imprint' must specify 'the name and address of the promoter of the material', and (where not the promoter) the name and address of any person on behalf of whom the material is being published. ${ }^{80}$ It applies to all materials, not merely those of campaigners registered with the ELC, and there are no minimum spending thresholds. The rule's

76 The rule applies to both candidates and to political parties and registered third party campaigners (RPA, s.110 and PPERA, s 143). As the rules are substantially aligned, the following focuses on the PPERA requirements only.

77 PPERA, s 143A(1). This provision has not been commenced for Northern Ireland.

78 PPERA, s 143A(1)(b)

79 PPERA, s 143A(2)(b)

80 PPERA, $s$ 143(2). The name and address of the printer of the material must also be included. 
application is not limited to the registered period. ${ }^{81}$ Printed materials in referendum campaigns are subject to similar requirements. ${ }^{82}$ The ELC has used its civil enforcement powers to enforce the imprint requirement ${ }^{83}$ although failure to comply also attracts criminal liability. ${ }^{84}$

In summary, the current electoral rules which govern political advertising are in need of reform to reflect the challenges of the digital environment. First, digital advertising expenditure has increased rapidly, but it is difficult to monitor directly given the opaque reporting requirements. Second, the ban on broadcast advertising is increasingly difficult to justify given the shift of campaigning to the online environment. Third, the imprint requirement does not apply to digital election materials, leaving a serious gap in the electoral rules. The following section now considers how these problems and others can and should be dealt with.

\section{THE OPTIONS FOR REFORM}

This section explains the potential reforms to electoral law to deal with the challenges of digital campaigning, especially those arising from the use of microtargeting. First considered are relatively modest changes to the reporting of campaign expenditure, to enable the ELC to monitor and capture all of the attendant costs of digital campaigning. One live controversy is

\footnotetext{
81 PPERA, s.143A(4).

82 PPERA, s 126.

83 There were 14 cases investigated between 2012 and 2018, see: https://www.electoralcommission.org.uk/ data/assets/pdf file/0009/151659/Cases-publication.pdf.
} 84 PPERA, s143; RPA, s 110. 
foreign spending on campaigns, and the apparent gaps in the present regime to deal with it effectively. Second, are two measures which are aimed at increasing transparency; a digital imprint requirement, and online repositories for campaign messages. Third, and more radical, is the possibility of placing substantive restrictions on microtargeting. These range from modest interventions (eg, stopping lookalike profiling) to a complete prohibition of targeting. As is discussed below, placing limits on political advertising will need to be carefully calibrated with Article 10 (ECHR). Another possible means of mitigating some of the harms of microtargeting is to regulate the 'truthfulness' of content. Finally, some of the issues around regulatory design need to be confronted.

(a) Reforming spending rules

The ELC has made a number of proposals to both increase the transparency of spending on digital campaigning, and to ensure all associated costs are captured. ${ }^{85}$ First, it argues for greater specificity in reporting. One particular problem is securing a correct division of spending between local and national campaigns. Clearly there is an incentive to report expenditure against the national spending limit, which is considerably higher, but digital communications are often focused on swing voters in marginal seats. To address this issue, the ELC proposes more specific information including on the messages used, the amount spent on each campaign, and which parts of the country the message was targeted at. ${ }^{86}$ Spending categories would also need

\footnotetext{
${ }^{85}$ See also DCMSC interim report, above n 4, para 48.

${ }^{86}$ ELC, above n 3, para 50.
} 
to be revised, as PPERA currently contains no separate category for digital spend. ${ }^{87}$ A second reform is to revise the rules to capture all digital campaigning costs. One seeming anomaly is money spent by political parties (and lead referendum campaigns) on direct staff costs not counting towards spending limits. ${ }^{88}$ It is clear parties have used permanent employees, and have taken on additional staff or consultants, at significant cost, for their digital campaigns. ${ }^{89}$ The ELC also stress that the spending limits do currently include all the costs of developing and using databases; this applies even if the original purchase of hardware and software falls outside the regulated period. ${ }^{90}$ The ELC notes that resources are needed to make and manage databases of supporters which can in turn lead to organic reach; these costs should count towards spending limits. ${ }^{91}$ So too the costs of bots and paid trolls. ${ }^{92}$

\footnotetext{
${ }^{87}$ Spending could be 'hidden' in other categories of spending (such as advertising agencies, market research etc) (CoE report, above n 2, p 17; UCL Constitution Unit Report of the Independent Commission on Referendums (July 2018) (hereafter 'ICR') para 14.16).

${ }^{88}$ ELC, above n 3, para 67 . It does count towards non-party campaigners and candidates' spending limits.

89 ibid, para 68-69.

$90 \mathrm{ibid}$, para 71. ELC is currently drafting statutory codes of practice which clarify the position, see: https://www.electoralcommission.org.uk/our-work/publications/consultations-and-responses/spending-bycandidates-and-political-parties-codes-of-practice

${ }^{91} \mathrm{ELC}$, above $\mathrm{n} 3$, para 66. 'Organic reach' is where a campaign message or advert is received by supporters who share the message further with their online contacts.

${ }^{92}$ ELC, ibid, para 28.
} 
One set of reforms the ELC has argued for relates to information and reporting requirements. Given the immediacy and ubiquity of digital campaigning, it stresses it needs to be able to investigate campaigns in 'real time', not just after a vote as at present. ${ }^{93}$ The reach of its powers to compel the provision of evidence also need to be extended to third parties, including social media platforms. ${ }^{94}$ Another of the major problems is the lack of effective sanctions the ELC has. At present, the maximum fine it can impose is $£ 20,000$ for each offence, which the ELC considers 'risks becoming a cost of doing business', with no effective deterrent value. ${ }^{95}$ This is particularly the case for referendums, where reputational damage is far less likely to be an issue for non-party campaigners. ${ }^{96}$

Another particular area of concern identified by the ELC is foreign spending in UK political campaigns. The only individuals or groups who can give money to parties or campaigns (or register as non-party campaigners) are people who live or are registered to vote in the UK and organisations based here. ${ }^{97}$ At the time PPERA was passed, there was limited potential for foreign actors to purchase campaign advertising. ${ }^{98}$ The internet has certainly made cross-border communication easier and cheaper for non-UK organisations. ${ }^{99}$ There exists a surprising lacuna

\footnotetext{
${ }^{93}$ ELC, above n 3, para 105-106. The ELC's investigatory powers are enumerated in PPERA, Sch.19B. 94 ibid, para 107.

$95 \mathrm{ibid}$, para 115. It should be noted, however, that criminal offences can be referred to the police and on conviction do carry significant penalties, including potential imprisonment.

96 ibid, para 116.

${ }^{97}$ PPERA, s 54 (on permissible donors to parties); PPERA, s.88 (on permissible third party campaigners). ${ }^{98}$ ELC, above n 3, para 87.

99 ICR, above n 87 para 14.13; ELC, above n 3, para 84.
} 
in the political finance regime: while there is a 'general principle' against foreign spending, there is no 'explicit' ban. ${ }^{100}$ Where a non-UK individual or organisation spends below the minimum levels requiring registration, there is no specific infraction of the UK electoral laws. ${ }^{101}$ Even were this apparent loophole to be removed, there would remain serious scope for abuse. ${ }^{102}$ While monitoring foreign interference in political campaigns will engage the intelligence and security services, ${ }^{103}$ in the view of the ELC, social media platforms must put in place mechanisms to ensure those paying for political advertising in the UK are actually based, or registered to vote, here. ${ }^{104}$ As the ELC noted, such arrangements had been put in place by Google, Facebook and Twitter in advance of the US mid-term elections in $2018 .{ }^{105}$ While there were reported problems with the schemes in the US, ${ }^{106}$ Facebook has subsequently announced a new enhanced registration procedure which requires those placing political advertisements on its

\footnotetext{
${ }^{100}$ ELC, above n 3, para 86.
}

$101 \mathrm{ibid}$, para 86. The relevant minimum in the 2017 general election was $£ 20,000$ (for England). The ICR makes a similar point in relation to referendums (ICR, above $n$ 87, para 141.5).

102 For evidence of potential/alleged Russian interference in the EU referendum see DCMSC interim report, above $\mathrm{n} 4$, ch 5 .

${ }^{103}$ ELC, above n 3, para 88-89.

104 ibid, para 90.

105 ibid. In the Irish May 2018 referendum, Facebook banned campaigners from outside Ireland buying referendum adverts, and Google banned all paid adverts connected with it (ibid, para 121). ${ }^{106}$ A Hern and J Waterson 'Facebook delays identity checks on UK political advertisers' The Guardian 7 November 2018. 
platforms to prove they are based in the UK. ${ }^{107}$ All this points to the ELC's increased reliance on intermediaries to ensure UK spending restrictions are enforced.

(b) Extending the imprint requirement to digital media

The apparently simple proposal to extend the 'imprint' rule to digital media has gained increasing traction. ${ }^{108}$ It represents a longstanding policy of the ELC, was recommended by the Law Commission (LC) in 2016, ${ }^{109}$ received the broad support of the DCMSC, ${ }^{110}$ and the Committee on Standards in Public Life endorsed the reform. ${ }^{111}$ Arising out of the Government's

${ }^{107}$ A Hern 'Facebook to require proof that political ads come from UK' The Guardian 29 November 2018. The information includes proof of UK (or EU) nationality (eg. a passport) and a UK postal address, Facebook 'Getting authorised to run ads related to politics or issues of national importance' (no date): https://www.facebook.com/business/help/208949576550051

108 The Secretary of State has a power to extend the imprint rule to digital media (PPERA, s 143(6)).

109 Law Commission, Scottish Law Commission, Northern Ireland Law Commission, Electoral Law: A Joint Interim Report (4 February 2016), p 156 available at https://s3-eu-west-2.amazonaws.com/lawcomprod-storage-11jsxou24uy7q/uploads/2016/02/electoral law interim report.pdf. The LC was only considering reform to RPA (it determined that PPERA and national campaign rules would not form part of its review given the politically contentious nature of the issues).

110 DCMSC final report, above n 4, para 211. Baroness O’Neill has introduced a Private Members Bill which requires the Government to extend the imprint requirement to digital communications, see: https://services.parliament.uk/bills/2017-19/electionsandreferendumsadvertising.html 111 Committee on Standards in Public Life Intimidation in Public Life Cm 9543, December 2017, p 61. 
response to the latter's report, the Cabinet Office launched a consultation on the issue, ${ }^{112}$ and a response to the consultation in May $2019 .^{113}$

The key challenge is to create a requirement which promotes transparency, while not having a chilling effect on online political discourse by ordinary citizens. ${ }^{114}$ Previous experience has demonstrated the difficulties in striking the appropriate balance. The Scottish Parliament had introduced a digital imprint rule for the independence referendum in $2014 .{ }^{115}$ While the intention was for the rule to apply only to campaigners, not individuals expressing personal opinions over social media, there was considerable confusion over its scope. ${ }^{116}$ The problem appeared to stem from the broad definition given to qualifying materials (those 'relating to' the referendum), rather than the narrower formulation used for print (those 'reasonably regarded' to

112 Cabinet Office, Protecting the Debate: Intimidation, Influence and Information: Responding to electoral recommendations and issues raised in the Committee on Standards in Public Life's report on Intimidation in Public Life (July 2018) pp 40-50.

${ }^{113}$ Cabinet Office Protecting the Debate: Intimidation, Influence and Information, Government response (2 May 2019) pp 32-37 (hereafter 'Government response').

${ }^{114}$ Electoral Reform Society, Protecting the Debate: Intimidation, Influence and Information: consultation response (18 October 2018).

115 Scottish Independence Referendum Act 2013 (Scotland), Sch 4, para 27.

116 ELC Scottish Independence Referendum (ELC/2014/02, December 2014) pp 110-111. 
intend to promote or procure a particular outcome). ${ }^{117}$ While the LC advocates the latter approach, in addition it suggests a 'reasonably practicable' defence for digital media. ${ }^{118}$

The Government's consultation raised a number of other issues. Recognising the dangers of over-inclusiveness, it floated the option of a spending threshold ${ }^{119}$ and suggested the digital imprint requirement should not apply outside of the regulated period, as is the case for the print equivalent. ${ }^{120}$ The Government now appears to favour parity with the imprint rule in these two respects. ${ }^{121}$ It also posed the question of whether certain types of digital messaging ought to be prioritised over others. ${ }^{122}$ No firm decision has been taken on this, though it observes that a differentiated approach may result in confusion. ${ }^{123}$

The issue of who should bear the responsibility for including an imprint, and liability for failing to do so, also needs to be settled. ${ }^{124}$ The potential addressees of a digital imprint rule could include, in the context of a 'tweet': the creator of the material, the advertising agency, the

117 Cabinet Office, above n 112, para 10.39.

118 LC, above n 109, para 11.76. For example, the requirement could be satisfied by including the imprint in the SMP biography rather than in the message itself. PPERA contains such a defence for the current imprint rule (s 143(10)).

119 Cabinet Office, above n 112, para 10.33.

120 ibid, p 46, Question 28.

121 Government response, n 113 above, pp 33-34.

${ }^{122}$ Cabinet Office, above n 112, paras 10.44-10.45.

${ }^{123}$ Government response, n 113 above, p 34.

124 Cabinet Office, above n 112, para 10.48. 
original tweeter, or an individual retweeting the message. ${ }^{125}$ Again the Government appears to be equivocating on this issue, noting the tension between ensuring that any rule promotes transparency for voters while not stifling the debate. ${ }^{126}$

The consultation also asked for views on the form an imprint should take, especially whether the imprint should appear as a 'pop up and hover' text, on the message itself, or whether inclusion of the author of the material on their social media 'bio' would be sufficient. ${ }^{127}$ The Government again appears to be postponing any real engagement with these difficult questions, stating only that any rule would need to be platform neutral. ${ }^{128}$

Clearly the issue of enforceability needs to be considered, given the ubiquity of social media. In response to the LC's consultation, it is noteworthy that the Association of Chief Police Officers entered serious reservations over the feasibility of a digital imprint rule. ${ }^{129}$ The ELC suggested criminal liability ought not to attach to non-compliance, though the LC demurred. ${ }^{130}$ The Government did not engage meaningfully with the question of enforcement, beyond asking

\footnotetext{
125 ibid, p 48, Question 33.

126 Government response, n 113 above, p 36.

${ }^{127}$ Cabinet Office, above n 112, para 10.46, Questions 30 and 31. The DCMSC has encouraged the government to consider the feasibility of 'clear, persistent banners on all paid-for political adverts and videos', indicating their source (DCMSC final report, above $\mathrm{n} 4$, para 211).

128 Government response, n 113 above, p 35.

129 LC, above n 109, para 11.74.

$130 \mathrm{ibid}$, para 11.81.
} 
whether current enforcement powers are sufficient. ${ }^{131}$ In its response to the consultation, the Government merely noted that substantial fines could be a means of ensuring compliance. ${ }^{132}$ Perhaps the major impediment to effective implementation of any digital imprint rule will be the enforcement resources available to the ELC (and the police).

There are clearly a number of difficulties in applying an imprint rule to digital communications and any regime would need to be 'future-proofed in expectation of developments in media and technology'. ${ }^{133}$ Whilst the Government appears to be asking (some of) the right questions, providing clear answers on appropriate rule design is proving problematic, and it is obvious a simple read across of the print rule is not appropriate, especially if priority is given to the need to protect political discourse online. Furthermore, while compliance among those who are registered with the ELC may well be high, there remain serious enforcement issues where organisations outside of the UK seek to influence campaigns.

The debate over digital imprints is not limited to the UK. Similar proposals have been considered in the US, with the introduction of bipartisan legislation (the 'Honest Ads Act') into Congress. ${ }^{134}$ The US Federal Election Commission (FEC) has also launched a consultation on

\footnotetext{
131 Cabinet Office, above n 112, p 49, Question 34.

132 Government response, n 113 above, p 37.

${ }^{133}$ Cabinet Office, above n 112, p 47, Question 32.

${ }^{134}$ See https://www.congress.gov/bill/115th-congress/senate-bill/1989/text. Proposals for similar legislation in Ireland have recently stalled (M O'Halloran 'Government defeated on online advertising and social media Bill' (The Irish Times, 14 December 2018)).
} 
extending imprint requirement to online advertisements. ${ }^{135}$ The EU's Code of Practice likewise advocates increasing transparency, requiring 'public disclosure of political advertising' online, ${ }^{136}$ though it also notes the need to avoid restrictions on political discussion or the publication of public opinion. ${ }^{137}$ What is significant is the response of the social media platforms. It appears the threat of legislation has resulted in both Facebook and Twitter implementing an imprint requirement in the US, ${ }^{138}$ and this has been extended by Facebook to the UK (using the US term 'disclaimer', rather than imprint). ${ }^{139}$ Perhaps this may yield more evidence on how to design a digital imprint rule which does not have the paradoxical effect of suppressing democratic discourse online.

(c) Database(s) of microtargeted advertisements

The provision of an online repository is a further initiative aimed at increasing the transparency of digital advertising. According to the Independent Commission on Referendums (ICR), such a

135 For background see https://www.fec.gov/updates/nprm-internet-communication-disclaimers-definitionpublic-communication-2018/

${ }^{136}$ EU CoP, above n 6, II.B.3.

137 ibid, II.B.4.

${ }^{138}$ S Wang, 'Twitter Follows Facebook in Endorsing Senate's 'Honest Ads' Act' (Bloomberg.com 10 April 2018) available at https://www.bloomberg.com/news/articles/2018-04-10/twitter-follows-facebook-inendorsing-senate-s-honest-ads-act

${ }^{139}$ Facebook 'How disclaimers work for ads related to politics or issues of national importance' (no date): https://www.facebook.com/business/help/198009284345835. For a fuller explanation of industry initiatives, see EU CoP, above n 6, Annex 2. 
database would serve two purposes: first, it would enable the ELC to assess online spending and identify any discrepancies in spending returns; and, second, it would increase the accountability of campaigns, exposing instances where contradictory messages are being targeted at different groups or where adverts are using inappropriate or harmful messages. ${ }^{140}$

Social media companies have already committed to doing this individually, as part of their initiatives to tackle 'dark ads'. ${ }^{141}$ For example, Facebook has put in place a repository for advertisements served over its platform which are 'related to politics or issues of national importance and target the UK'; ${ }^{142}$ those which do not carry 'disclaimers' and are reported by users to be of a political nature will also be added to the database. ${ }^{143}$ While this may increase the transparency of online campaigning, the database will only carry limited information on

$140 \mathrm{ICR}$, above $\mathrm{n} 87$, para 14.38 .

${ }^{141}$ A Hern and J Waterson 'Facebook cracks down on 'dark ads' by British political groups' The Guardian, 16 Oct 2018.

142 Facebook 'About the Ad Library' (no date) available at https://www.facebook.com/business/help/2405092116183307

${ }^{143}$ Facebook 'How are ads related to politics and national issues identified on Facebook?' (no date) available at https://www.facebook.com/help/180607332665293. 
targeting. ${ }^{144}$ The EU code would appear to require more, stipulating that users should be given information 'to understand why they have been targeted by a given advertisement'. ${ }^{145}$

While the platforms' moves to create repositories of political advertisements has been welcomed, a number of bodies and organisations have questioned whether this can be an effective substitute for a central public register. The ICR points to possible problems if each platform follows its own approach, with the resulting information being 'confusing and disjointed'. ${ }^{146}$ Instead, it stresses the need for coordination and cooperation between firms, government, parliament and the regulators. ${ }^{147}$ The DCMSC, which supports calls for an independent public register, ${ }^{148}$ also suggests the Government should impose 'transparency requirements' on SMPs, ensuring data on political advertising 'are clear and easily searchable, and identify the source, explaining who

144 The information will include: the number of 'impressions' (as a range); the amount spent (as a range); demographic information (age and gender); and the location of those who viewed the ads. Other platforms are reported to be planning similar measures (Hern and Waterson, above $n$ 141); for information on Twitter see: https://blog.twitter.com/official/en us/topics/company/2018/Providing-MoreTransparency-Around-Advertising-on-Twitter.html

${ }^{145}$ EU CoP, above n 6, II.B.

146 ICR, above $\mathrm{n} 87$, para 14.12 .

147 ibid, para 14.43.

${ }^{148}$ DCMSC interim report, above n 4, para 142; DCMSC final report, above n 4, para 215. 
uploaded it, who sponsored it, and its country of origin'. ${ }^{149}$ The ELC welcomes the initiatives of the platforms, although it appears less committed to a central register. ${ }^{150}$

(d) Restricting digital campaigning

This brief section, in the light of there being no case in point, discusses the principles enunciated by the Court in the $A D I$ case and others, and the extent to which it is possible to place restrictions on microtargeting consistent with freedom of political expression under Article $10 .{ }^{151}$ It then goes on to reflect upon some of the restrictions which could be placed on digital campaigning, including microtargeting.

\section{(i) FREEDOM OF POLITICAL EXPRESSION AND THE STRASBOURG JURISPRUDENCE}

As the Court has confirmed on numerous occasions, political expression, including advertising, benefits from the highest level of protection under Article 10, ${ }^{152}$ with States enjoying a narrow margin of appreciation in determining whether a restriction is necessary to address a pressing

149 DCMSC interim report, ibid, para 144. The ICR stresses that any database would need to be searchable and have detailed comprehensive information (ICR, above n 87 para 14.39).

150 ELC, above n 3, para 61.

${ }^{151}$ For a fuller exposition and critique of the Court's case law see Rowbottom, above n 74; Lewis, above $n$ 74.

152 TV Vest, above n 75, [66]. 
social need. ${ }^{153}$ Clearly, any restrictions on targeted advertising is likely to engage Article $10 .{ }^{154}$ Nevertheless, the Court has repeatedly stated that restrictions on political advertising are permissible to prevent a distortion of the democratic process. ${ }^{155}$

One of the crucial issues in the $A D I$ case concerned the availability of less restrictive means in the alternative to a general prohibition on political advertising over broadcast media. First, the Court was persuaded, in determining the proportionality of a measure, it must 'primarily assess the legislative choices underlying it' ${ }^{156}$ Second, in the context of prohibition, it was appropriate for a State to 'take into account the risk of abuse if a general measure were to be relaxed'. ${ }^{157}$ Further, where a relaxation would 'give rise to a risk of significant uncertainty, of litigation,

${ }^{153} A D I$, above $\mathrm{n} 73,[101]$.

154 Zuiderveen Borgesius et al., above n 29, p 92. Article 10 protects 'the means of transmission or reception since any restriction imposed on the means necessarily interferes with the right to receive and impart information' (Autronic AG v Switzerland (1990) 12 EHRR 485 [47]).

155 TV Vest, above n 75, [70]; VgT, above n 75, [73].

${ }^{156} A D I$, above $\mathrm{n} 73,[108]$ and [114-116].

157 ibid, [108]. The risk of abuse in this context was relaxation of the prohibition, to allow political advertising by social advocacy groups outside of an election period might give rise to the risk that 'wealthy bodies with agendas being fronted by social advocacy groups created for that precise purpose', thereby circumventing the financial caps on advertising (ibid, [122]). This is something of a false argument since expenditure outside of the regulated period does not count towards party election expenditure. 
expense and delay, as well as of discrimination and arbitrariness, ${ }^{158}$ these were factors relevant to the UK's assessment of whether a general measure was preferable. ${ }^{159}$

One of the arguments in favour of the prohibition turned on the particular potency of broadcasting advertising relative to other forms, including online. The Court accepted the differential treatment of broadcasting still to be logically cogent, recognising 'the immediate and powerful effect of the broadcast media, an impact reinforced by the continuing function of radio and television as familiar sources of entertainment in the intimacy of the home'. ${ }^{160}$ In contrast, 'the choices inherent in the use of the internet and social media mean that the information emerging therefrom does not have the same synchronicity or impact as broadcasted information'. 161

Whether the Court's observations on the relative power of broadcasting advertising stand up to scrutiny, both then and now, is a matter of debate. As early as 1998, the Committee on Standards in Public Life (the 'Neill Committee') noted the advent of the internet and digital communications could render the broadcasting ban out of date. ${ }^{162}$ However, rather than justifying its removal, the Committee called for the legislation governing political advertising on

\footnotetext{
158 ibid, [108] (authorities omitted).

159 ibid, [108 and 110].

160 ibid, [119] (authorities omitted).

161 ibid, [119]. See also R (Animal Defenders International) $v$ Secretary of State for Culture, Media and Sport [2008] UKHL 15 [30] per Lord Bingham.

162 Neill Committee, above $\mathrm{n}$ 1, para 13.35. It recommended that the ELC keep the rules under constant review (ibid, 183, Recommendation 97).
} 
broadcast media to be reviewed 'to ensure that its reach is sufficiently wide to block attempts at evasion by new modes of communication' ${ }^{163}$ More recently the ICR suggested social media may have overtaken broadcasting as the most influential form of media, it being 'far from clear that social media lack "intimacy" or that exposure to advertising online is a matter of consumer choice'. ${ }^{164}$ So if a ban can be justified when broadcasting was the most influential media, why cannot the same be true in principle for its successor?

The immediate problem with applying the reasoning of the Court in $A D I$ to digital campaigning is its apparent inconsistency with previous case law, especially the $T V$ Vest judgment. ${ }^{165}$ Nevertheless, the Court has accepted States may impose restrictions on political advertising to protect the integrity of the democratic process. While the rights to both freedom of expression and free elections, 'form the bedrock of any democratic system' and are 'inter-related and operate to reinforce each other', ${ }^{166}$ the Court has acknowledged there are certain circumstances where the 'two rights may come into conflict and it may be considered necessary, in the period preceding or during an election, to place certain restrictions, of a type which would not usually be acceptable, on freedom of expression'. ${ }^{167}$

\footnotetext{
163 ibid, p 176, Recommendation 94. For a similar view see Rowbottom, above n 74, pp 12-13.

164 ICR, above n 87 para 14.35 .

165 Zuiderveen Borgesius et al., above n 29, p 94. The facts of the TV Vest, above $n$ 75, were very close to those of $A D I$. The former involved the application of a general broadcast ban to a small political party, vitiating the justification for the measure, namely to prevent a potential distortion of the democratic process by powerful financial interests.

166 Bowman v UK (1998) ECHR 4 [42].

167 ibid, [43].
} 
Further, as the $A D I$ case demonstrates, in judging the necessity of a restriction, the Court has had regard to the potential for abuse if a less restrictive mechanism were put in its place. So, in the context of microtargeting, if measures aimed to mitigate some of its harmful consequences proved to be unsuccessful, there is a stronger justification for more robust mechanisms (perhaps even a ban). The behaviour of those who bear the responsibility for making a system work especially campaigners and intermediaries - and their willingness to ensure any regulatory solutions are effective and workable are clearly relevant to any evaluation of whether more restrictive means are necessary in the future. This raises the question of what types of further restrictions could be contemplated?

\section{(ii) POSSIBLE RESTRICTIONS OF MICROTARGETING}

There a number of ways in which microtargeting could be subject to substantive restrictions in order to mitigate some of its more harmful potential, though there is as yet little consensus around any. Notably, as an industry body, the Institute of Practitioners in Advertising (IPA) has called for a temporary moratorium, with the prospect of an agreed minimum limit upon the number of voters sent an individual message. ${ }^{168}$ Explaining its reasoning, the IPA opined that the 'open, collective debate', upon which politics and the 'public sphere' depends, is being

168 DCMSC interim report, above n 4, para 141; IPA, Written evidence submitted by the Institute of Practitioners in Advertising (FKN0093, June 2018) para 16 available at http://data.parliament.uk/WrittenEvidence/CommitteeEvidence.svc/EvidenceDocument/Digital,\%20Culture \%20Media\%20and\%20Sport/Fake\%20news/written/84205.html 
circumvented by microtargeting. ${ }^{169}$ The ICR considered the idea of a total ban on online political advertising, as an extension of the UK's approach to broadcast media. ${ }^{170}$ While restricting political speech, it observed that campaigners could still communicate with voters through 'organic' content, with online reach being determined by their level of public support rather than advertising spend. ${ }^{171}$ It cautioned against such a move, however, on the basis it would lead to disparity of treatment between print and digital advertising that would be difficult to justify. ${ }^{172}$ Instead it recommended a review of political advertising across all media. ${ }^{173}$

The DCMSC was similarly equivocal, arguing the ELC should establish a code of practice on microtargeting, perhaps limiting its use, during the regulated period, to those registered with the ELC. ${ }^{174}$ In addition, the Committee argued the ELC (and Information Commissioner's Office (ICO)) should consider the 'ethics' of SMPs selling lookalike audiences to advertisers during the regulated period (in particular, whether users should have the right to opt out from being included in lookalike profiling). ${ }^{175}$ Elsewhere it rejected an outright ban, arguing that microtargeting 'when carried out in a transparent manner, can be a useful political tool'. ${ }^{176}$

\footnotetext{
169 ibid, para 14.

170 ICR, above n 87 para 14.31.

171 ibid, para 14.32.

172 ibid, para 14.33.

173 ibid, p 187, Recommendation 61.

174 DCMSC interim report, above n 4, para 50; see also DCMSC final report, above n 4, para 216.

175 ibid, para 50.

176 ibid, para 141.
} 
At present, it appears there is no clear appetite for substantive restrictions on microtargeting, though the political consensus may shift, especially if other measures aimed at its control, particularly those focused at increasing transparency, do not prove to be successful. What is perhaps surprising at this stage is the lack of a clear signal to intermediaries that unless its harmful effects are mitigated, microtargeting will be curtailed. This may blunt the potential leverage government and the regulators have over the industry to achieve meaningful reforms.

(iii) REGULATING FOR THE ‘TRUTHFULNESS’ OF DIGITAL CAMPAIGNING

One of the core objections to microtargeting is it enables campaigners to escape public scrutiny of the content of their political messages. This raises the issue of whether campaign content should be regulated, particularly the factual basis for any underlying claims being made? ${ }^{177}$ For a number of years, it has been the position there is no direct regulation of the 'truthfulness' of campaign materials. ${ }^{178}$ The ELC has consistently rejected any such role for itself. ${ }^{179}$

\footnotetext{
177 The UK Statistics Authority can complain to campaigners if it thinks they have misrepresented official statistics in their campaign materials.

178 Note it is an offence to make or publish a false statement of fact about the personal character or conduct of a candidate (RPA, s.106). This is narrowly constructed; the provision does not reach allegations political in nature, and so it is not discussed further here.

179 ELC, above n 3, para 34.
} 
The Advertising Standards Agency (ASA) likewise does not have role in regulating election and referendum advertising ${ }^{180}$ (but it does oversee adverts relating to some non-party political subjects ${ }^{181}$ ). Before 1999, party political advertising did fall within its remit, but some of the general rules did not apply, specifically those prohibiting misleading advertisements, making unfair comparisons or unfairly attacking or discrediting other 'products'. In the ASA's opinion this 'part in, part out' approach risked bringing 'advertising in general into disrepute with the public'. ${ }^{182}$ It was also concerned that, given the short campaign timeframes, it was unlikely any decision could be made before an election's conclusion. ${ }^{183}$ More significant was the lack of a political consensus between the main parties to bring advertising wholly within the code. ${ }^{184}$

The Neill Committee in 1998 'exhorted' the political parties to formulate a bespoke code of practice, in consultation with the advertising industry, although it noted any such code would 'have to be robust enough to be effective in the heat of a general election campaign'. ${ }^{185}$ The

180 See ASA CAP Code, clause 7.1 available at https://www.asa.org.uk/type/non broadcast/code section/07.html

${ }^{181}$ For further background see ASA 'Political advertising complaints' (26 May 2016) available at https://www.asa.org.uk/news/political-advertising-complaints.html\#.V6CoyqUUXRU.

182 Home Office, The Funding of Political Parties in the United Kingdom: The Government's proposals for legislation, in response to the Fifth Report of the Committee on Standards in Public Life, Cm 4413, July 1999, para 9.8 .

${ }^{183}$ ASA, above n 181.

${ }^{184}$ Government response to Neill Committee, above n 182, para 9.8; ASA, above n 181.

185 Neill Committee, above n 1, para 13.24, Recommendation 96. 
government of the day was robust in its rejection of the (soon to be formed) Electoral Commission as a possible regulator:

'The Electoral Commission has been canvassed as a possible alternative regulatory body. The Government, however, sees dangers in conferring such a role on the Electoral Commission. Adjudicating over complaints about political advertisements would inevitably draw the Electoral Commission into the party political arena in a way that could compromise its reputation for even-handedness and independence.' ${ }^{\text {186 }}$

It did not provide any alternative candidates. ${ }^{187}$

The ELC revisited the question of if and how to regulate political advertising in $2004{ }^{188}$ It ruled out a statutory code, given the freedom of expression concerns, and the scope of any voluntary code could not, in its view, reach the truthfulness of campaign messages: 'it would seem inappropriate and impractical to seek to control misleading or untruthful advertising, given the often subjective nature of political claims'. ${ }^{189}$ It also rehearsed many of the practical problems with trying to enforce a code - the need for expeditious decisions, the potential for spurious

186 Government response to Neill Committee, above n 182, para 9.9.

187 ibid, para 9.10.

${ }^{188}$ ELC, Political advertising: Report and recommendations (June 2004) available at https://www.electoralcommission.org.uk/ data/assets/pdf file/0007/213784/Political-Advertising-reportand-recommendations-June-2004.pdf

189 ibid, p 4. 
complaints, the need for an independent adjudicatory body (rejecting itself as a candidate, together with the ASA model), and the lack of any effective sanctions. Again, the biggest obstacle to the adoption of a regulatory framework was the lack of consensus among the political parties. ${ }^{190}$ This apparent political impasse has now persisted for over two decades.

While there currently exists no regulation of political advertising content, the ELC and ASA do nevertheless receive a substantial number of complaints on political advertising during political campaigns (eg, the ELC received in excess of 1,000 complaints from the public concerning the accuracy of campaign literature during the EU referendum). ${ }^{191}$ This appears to suggest there is a public demand for regulation, as is clear from public opinion research. ${ }^{192}$ Indeed, in evidence before the DCMSC, Guy Parker (CEO of the ASA) accepted there is a general public consensus that the content of political advertising should be regulated; the 'difficulty is by who and how'. ${ }^{193}$ Regulation would also need 'buy-in' which has not been forthcoming from political parties. ${ }^{194}$

190 The Conservative Party stated that it would not abide by a code, while Labour did not respond to the consultation (ibid, pp 4-5).

191 I White, N Johnston and E Uberoi Referendum campaign literature Commons Briefing papers CBP7678, September 2016, pp 11-12, p 15; M Sweney and J Plunkett, 'Ad watchdog powerless to act on controversial Brexit campaigns' The Guardian 28 Jun 2016.

192 eg, GfK Political finance regulation and digital campaigning: a public perspective (24 April 2018) pp 39-

42.

${ }^{193}$ DCMSC interim report Oral evidence: Disinformation and 'fake news', HC 363, 6 November 2018, Q4103.

194 ibid, Q4102. 
Another possible solution is to require social media firms to regulate the content of political messages on their platforms. As the ICR has observed, in the broader context of disinformation, this carries potentially 'dangerous consequences for freedom of expression’ with SMPs, especially in the shadow of sanctions, having an incentive 'to err on the side of caution' rather than carefully balancing harm against freedom of expression. ${ }^{195}$ Alternatively, the EU Commission envisages a greater role for 'fact-checkers', with the creation of an independent European network. ${ }^{196}$ Some have gone further, calling for the creation of a 'truth commission' to intervene to expose misleading campaign claims. ${ }^{197}$ Others have canvassed the idea of preclearance of factual claims made in political advertisements. ${ }^{198}$ While fact-checking may have an important role to play, practical problems abound, not least how to reach the voters who were originally targeted?

The simple hard fact is there is unlikely to be the political desire or will to put in place a robust regulatory regime for political advertising content while, as microtargeting increases in scale and ubiquity, the need and demand for it continues to grow. Regulation is probably always going to be an ineffective substitute for the glare of public and media scrutiny which microtargeting tends to obscure.

195 ICR, above n 87, para 14.26.

196 Commission Communication, above n 5, p 9.

197 White et al., above n 191, pp 17-18.

198 eg, Coalition for Reform in Political Advertising (cited by DCMSC final report, above n 4, para 209). 
(e) The regulatory perspective: 'speaking softly carrying big sticks'?199

It has already been noted that social media companies have implemented a number of reforms to guard against the distortion of the political debate in the UK and beyond. In particular, progress has been made include the display of 'disclaimers' and the provision of online repositories. These initiatives have been broadly welcomed, though the ELC has stated that if the industry's 'voluntary' proposals do not work, the Government should consider direct regulation. ${ }^{200}$ On both these reforms, the Government have committed to including them in a code of practice, ${ }^{201}$ as part of its broader initiatives to deal with 'online harms'. ${ }^{202}$ The code, which will also include fact-checking requirements, ${ }^{203}$ would be backed up by regulator with significant enforcement powers (including the ability to impose substantial fines and, as a last resort, 'ISP blocking' powers for non-compliant platforms). ${ }^{204}$

The EU Commission's efforts in implementing its Code of Practice has also become a focal point for reform. In anticipation of the European Parliament elections of May 2019, the Commission stepped-up its monitoring of the Code's implementation, with requirements on its

\footnotetext{
199 J Braithwaite 'On Speaking Softly and Carrying Big Sticks: Neglected Dimensions of a Republication Separation of Powers' (1997) 47(3) The University of Toronto Law Journal 305.

200 ibid, para 125.

${ }^{201}$ House of Commons Digital, Culture, Media and Sport Committee Disinformation and 'fake news': Final Report: Government Response, HC 2184, 9 May 2019, pp 10 and 12.

202 HM Government Online Harms White Paper Cm 57, April 2019.

203 ibid, para 7.28.

204 ibid, para 6.5.
} 
signatories to report monthly on progress. ${ }^{205}$ The Commission has been highly critical of the major platforms, for example, in failing to provide 'hard data'. ${ }^{206}$ Nevertheless, the industry have made significant moves to increase transparency. ${ }^{207}$ Reporting after the conclusion of the elections, the Commission was able to announce progress, while leaving open the option to legislate in the future. ${ }^{208}$

While not the focus of this paper, data protection and privacy laws may be another regulatory vehicle to deal with microtargeting. ${ }^{209}$ Under the General Data Protection Regulation (GDPR) ${ }^{210}$ the processing of data pertaining to 'political opinions' (a category of 'sensitive data') is prohibited subject to strictly limited exceptions. ${ }^{211}$ It also contains a public interest exception,

205 European Commission 'A Europe that Protects: The EU steps up action against disinformation', Press Release (5 December 2018) available at: http://europa.eu/rapid/press-release IP-18-6647 en.htm ${ }^{206}$ European Commission 'Statement on the Code of Practice against disinformation: Commission asks online platforms to provide more details on progress made' Statement, 28 February 2019 available at: http://europa.eu/rapid/press-release STATEMENT-19-1379 en.htm

${ }^{207}$ For a summary of progress see: https://ec.europa.eu/digital-single-market/en/news/76092/76079 ${ }^{208}$ European Commission Report on the implementation of the Action Plan Against Disinformation, JOIN(2019) 12 final (14 June 2019).

${ }^{209}$ CJ Bennett 'Voter databases, micro-targeting, and data protection law: can political parties campaign in Europe as they do in North America?' (2016) 6(4) International Data Privacy Law 261-275; EDPS report, n 7 above, pp 13-16; Zuiderveen Borgesius, n 29 above, pp 90-91.

${ }^{210}$ Regulation (EU) $2016 / 679$ on the protection of natural persons with regard to the processing of personal data and on the free movement of such data (OJ [2016] L 119 1). 211 GDPR, Article 9(2)(a, d, e). 
permitting the processing of data on political opinions 'in the course of electoral activities' ${ }^{212}$ According to the ICO, where political campaigners make use of data analytics, aggregating data from SMPs and other sources, it must inform the data subjects, although a public statement on the organisation's website may suffice. ${ }^{213}$ The EU Commission's guidance notes 'when lifestyle data brokers or platforms collect data for commercial purposes, that data cannot be further processed in the electoral context'. ${ }^{214}$ Similarly, the European Data Protection Board (EDPB) recently reiterated the requirement of explicit consent for automated profiling. ${ }^{215}$

There are also restrictions on campaigning by political organisations under the ePrivacy Directive. ${ }^{216}$ As a form of direct marketing, 'unsolicited' political communications may require consent. $^{217}$ Since 2009, that Directive also requires prior consent to the storage of cookies and

212 GDPR, Article 9(2)(g) and Recital 56.

${ }^{213}$ ICO Guidance on political campaigning (28 March 2018) paras 79-82.

${ }^{214}$ EU Commission Free and Fair elections: Commission guidance on the application of Union data protection law in the electoral context $\operatorname{COM}(2018) 638$ final (12 September 2018) p 6.

215 EDPB Statement 2/2019 on the use of personal data in the course of political campaigns (13 March 2019). See also ICO Guidance, n 213 above, paras 76-82.

${ }^{216}$ Directive 2002/58/EC concerning the processing of personal data and the protection of privacy in the electronic communications sector (as amended by Directive 2009/136/EC). The Directive is implemented in the UK pursuant to the Privacy and Electronic Communications Regulations (PECR) SI 2003/2426 (as amended).

${ }^{217}$ Article 13; ICO Guidance, n 213 above, para 12-14. See also EDPS, n 7 above, p 14. The ICO relied upon the decision of the Information Tribunal in Scottish National Party v Information Commissioner (EA/2005/0021, 15 May 2006). 
other tracking technologies on end users' devices. ${ }^{218}$ There is currently a draft ePrivacy Regulation ${ }^{219}$ which, if adopted, would significantly restrict the use of 'metadata', a matter of particular controversy. ${ }^{220}$

Both the GDPR and ePrivacy rules offer the potential to substantially restrict microtargeting, although much depends upon whether data protection authorities have the resources and incentives to enter an inherently political arena. ${ }^{221}$ Nevertheless, recent experience in the UK has shown an increasing willingness of the ICO to intervene, both in individual cases ${ }^{222}$ and the broader policy debate, with the Information Commissioner arguing for an 'ethical pause' on microtargeting. ${ }^{223}$ The critical question here is the extent to which it is desirable to use data

\footnotetext{
${ }^{218}$ Article 5(3).

219 Proposal for a Regulation of the European Parliament and of the Council concerning the respect for private life and the protection of personal data in electronic communications and repealing Directive 2002/58/EC (Regulation on Privacy and Electronic Communications) COM/2017/010 final. The latest version of the Regulation emerging from the Council is available at: https://data.consilium.europa.eu/doc/document/ST-7099-2019-INIT/en/pdf 220 On the (initial) draft proposal see WG Voss 'First the GDPR, Now the Proposed ePrivacy Regulation' (2017) 21(1) Journal of Internet Law 3; Article 29 Working Group Opinion 01/2017 on the Proposed Regulation for the ePrivacy Regulation (2002/58/EC) (12 February 2018).

221 Zuiderveen Borgesius, n 29 above, p 91; Bennett, n 209 above, p 275.

${ }^{222}$ For a summary of ICO enforcement action see: https://ico.org.uk/action-weve-taken/investigation-intodata-analytics-for-political-purposes/

${ }^{223}$ DCMSC Oral evidence: Fake News, HC 363, 6 November 2018, Q4011, Elizabeth Denham. The ICO is also consulting upon a code of practice, see: https://ico.org.uk/about-the-ico/ico-and-stakeholderconsultations/call-for-views-code-of-practice-for-the-use-of-personal-information-in-political-campaigns/
} 
protection and privacy laws as a means of regulating microtargeting. There is the possible danger that freedom of political expression will not be given appropriate weight when it comes to the careful balancing of rights necessary in designing appropriate restrictions on digital campaigning.

It appears then that there is an emerging consensus on the need to regulate online advertising, and the industry has made efforts to ensure political campaigning on their platforms are more closely aligned to the underlying norms of electoral law, especially as regards transparency. Indeed, in this regard, it is significant that Mark Zuckerberg (the CEO of Facebook) has called for legislation to regulate digital campaigning. ${ }^{224}$ The emerging solution is a system of coregulation, whereby government and regulatory agencies frame principles and guidelines at a formal level, with implementation resting with the industry. The likelihood of such measures achieving success depends upon the credibility of threats to intervene with sanctions, and even direct regulation, should industry-led initiatives fail.

\section{CONCLUSIONS}

As one of the leading critics of microtargeting observes, "we have anxieties about microtargeting because we have anxieties about democracy itself' ${ }^{225}$ So we should caution judging

${ }^{224}$ Mark Zuckerberg 'The Internet needs new rules. Let's start in these four areas' The Washington Post 30 March 2019.

${ }^{225}$ D Kreiss 'Micro-targeting, the quantified persuasion' (2017) 6(4) Internet Policy Review available at https://policyreview.info/articles/analysis/micro-targeting-quantified-persuasion 
this practice against an idealised version of democracy, where voters are rational and seek to be informed, shaping their preferences in the general interest. Furthermore, we know that despite the apparent appetite of political parties to use political advertising generally, there is evidence that it has limited persuasive effects. ${ }^{226}$ That said, the so-called 'minimal effects thesis' tends to underplay the ability of political advertising to increase the saliency of particular types of issues, especially those of an emotional nature, likely to invoke feelings of fear and anxiety. ${ }^{227}$

While the evidence of the effects of digital campaigning generally may be ambiguous, there are specific techniques and consequences associated with microtargeting which give rise to particular unease. Principal among these is the danger that targeting allows politicians to communicate with voters in an unmediated way, thereby escaping the glare of public scrutiny, and undermining the integrity of the public sphere. Increasing the transparency of online advertising, while necessary, is only a partial solution to this problem. A digital imprint requirement will contribute to transparency, but enforcement brings with it a new set of problems, not least the potential 'chilling effect' of online political discourse. And as

${ }^{226}$ For an overview of the evidence in the US, see JL Kalla and DE Broockman 'The Minimal Persuasive Effects of Campaign Contact in General Elections: Evidence from 49 Field Experiments' (2018) 112(1) American Political Science Review 148.

${ }^{227}$ For an overview of the literature see MP Motta and E Fowler 'The Content and Effect of Political Advertising in U.S. Campaigns' in WR Thompson (ed) Oxford Research Encyclopedia of Politics (Oxford: OUP, 2016). 
microtargeting becomes more efficient, online repositories are likely to be 'overwhelmed' by the ever increasing volumes of messages generated. ${ }^{228}$

A different way of framing the question is to ask what 'value' does microtargeting have, ensuring we continue to benefit from innovations in digital campaigning. It would certainly be useful if there was further evidence of the effects of microtargeting, both positive and negative. ${ }^{229}$ Any case for reform is clearly easier to advance if regulation itself is targeted; seeking to mitigate some of the less palatable consequences of the practice, while not stultifying some of the potential benefits. To this end, attempts to regulate the content of political campaign messages, either by the intermediaries or through direct regulation, are likely to be fraught with dangers, restricting political speech in a way which is inimical to democracy. The best solution is to increase the transparency of political campaigning through imprint requirements and the use of digital repositories. Nevertheless, restrictions on the means of communication can and should be considered in the future if less restrictive measure prove to be unsuccessful. The risk to democratic discourse is sufficient to justify restrictions on microtargeting, as a last resort.

As we have seen previously, it is very difficult to build a consensus among politicians and their parties over regulating political advertising. Politicians are alert to digital campaigning as a means of securing a comparative advantage over their adversaries. Perhaps the 'arms race' narrative, so successfully employed in the UK to justify the ban on broadcast advertising, is now

${ }^{228}$ IPA 'IPA to call for moratorium on micro-targeted political ads online' Press Notice 20 April 2018 available at https://ipa.co.uk/news/ipa-to-call-for-moratorium-on-micro-targeted-political-ads-online 229 Zuiderveen Borgesius et al., above n 29, p 96. 
being realised in the online environment. Is it likely that politicians will be able to remove from themselves the use of such a powerful and efficient campaigning tool? Even if the political class are persuaded of the need for regulation, are the regulators likely to enthusiastically assume the mantle? Mindful of the need to protect the perception of their independence, would any rational regulator want to adjudicate on a political party's marketing behaviour in the heat of an electoral campaign? What might be the possible implications for that regulator, and its personnel, after the polls have closed?

Freedom of political expression is a core value in any democratic state, and any restrictions upon it need to be justified carefully and fully. Nevertheless, online political advertising is changing the nature of our campaigns, our politics and, ultimately, our democracy; for this reason it must not escape the most intense scrutiny, now and in the future. 